Review Article
$\mathrm{J}$ Exp Clin Med

2021; 38(S1): 44-52

doi: $10.52142 /$ omujecm.38.si.gastro.6

\title{
ERCP-related bleeding
}

\author{
Abdullah Emre YILDIRIM ${ }^{1, *[i]}$
}

${ }^{1}$ Department of Gastroenterology, Faculty of Medicine, University of Gaziantep, Gaziantep, Turkey

\begin{abstract}
\begin{tabular}{ccccc}
\hline Received: 20.07 .2020 & $\bullet$ & Accepted/Published Online: 10.11 .2020 & $\bullet$ & Final Version: 18.03 .2021 \\
\hline
\end{tabular}
Abstract

Clinically significant bleeding is an uncommon complication of diagnostic endoscopic retrograde cholangiopancreatography. But the endoscopists needs to be skilled at prevention and management. Post ERCP bleeding is most often seen following sphincterotomy. The overall risk of bleeding in patients undergoing sphincterotomy is approximately 1-2 percent. Most bleeding episodes are mild to moderate in severity. The risk of bleeding can be minimized by identifying patients at risk, correcting coagulation abnormalities and careful technique by skilled endoscopists in high-volume centers. Post-sphincterotomy bleeding often stops spontaneously and is rarely life-threatening, except in patients with a bleeding diathesis. Most clinically relevant bleedings can be managed with medical treatment and/or endoscopic therapy, which should be performed without delay in patients who have immediate bleeding. Endoscopic therapy options include epinephrine injection, hemostatic clips, thermal therapy and placement of full covered self-expandable metal stents. Angiography or surgery is usually reserved for patients with refractory bleeding and is rarely required.
\end{abstract}

Keywords: ERCP, ERCP adverse event, ERCP Bleeding, Post ERCP haemorrhage

\section{Introduction}

Endoscopic retrograde cholangiopancreatography (ERCP) remains the standard and invaluable procedure for diagnosis, evaluation, and management of pancreaticobiliary disorders. Over time, the role of ERCP has evolved from a diagnostic to therapeutic intervention because of improvements in other imaging modalities. While this expansion has improved treatment modalities for biliary pathology, complications and adverse events following ERCP continue to persist and may have a significant impact on patients' morbidity and rarely mortality (Talukdar, 2016).

Diagnostic ERCP alone or with associated pancreaticobiliary instrumentation and therapy may cause a variety of complications and adverse events, including pancreatitis, hemorrhage, cholecystitis, infection, intestinal perforation and cardiopulmonary events. These adverse events ranges from full recovery after an additional few days of hospitalization to severe and devastating outcomes such as permanent disability or death. Adverse events, along with increased morbidity, may also cause significant concern for the endoscopist and exposure to medical malpractice claims. Though ERCP is considered to be safe and effective, it carries the highest risk of procedure-related complications among all endoscopic procedures. Despite advances in endoscopic technology, better operator experience and research-driven safety protocols, the incidence of ERCP-related complications and mortality remains relatively constant. Several distinct studies reported a relatively consistent frequency of ERCP complications and mortality rates over a decade between 10 $12 \%$ and $0.4-1.4 \%$, respectively (Siiki et al., 2012; Kapral et al., 2012; Glomsaker et al., 2013)

Bleeding is one of the most feared complications of therapeutic biliary endoscopy. Although it has become a relatively rare complication of ERCP due to advances in equipment and skills, it is still a problem. It is critical for the endoscopist to understand how to avoid and treat adverse events. This chapter will focus on bleeding-related adverse events, including risk factors, prevention, and management.

The most common cause of ERCP-related bleeding is endoscopic biliary and/or pancreatic sphincterotomy, which has been reported in as few as $0.1 \%$ but up to $2 \%$ of cases (Chandrasekhara et al., 2017). The true incidence is unknown, and variable rates are described due to retrospective study design, lack of standardized definitions and insufficient data on relevant patient and physician factors. Bleeding seen endoscopically during sphincterotomy is often reported as an adverse event, but itself does not represent an adverse outcome to the patient unless there is clinically significant blood loss or a change in management.

\section{Classification and grading}

A more recent statement by the American Society for Gastrointestinal Endoscopy (ASGE) defines bleeding as 
hematemesis and/or melena or a hemoglobin drop $>2 \mathrm{~g}$ following a procedure (Cotton et al., 2010). Bleeding after ERCP is classified as either immediate (intraprocedural or immediately after) or delayed (hours to weeks post-procedure with late being any time after 14 days). Delayed bleeding occurs from hours up to several weeks after endoscopic sphincterotomy and/or endoscopically interventions. Furthermore, bleeding can be classified as clinically significant (mild, moderate, and severe) or insignificant, based on the presence or absence of overt GI bleeding and/or change in hemoglobin level or the requirement for a secondary intervention such as endoscopy or blood transfusion.
The initial grading system proposed by Cotton et al. defined the severity of ERCP-related adverse events according to the number of transfused units and requirement for angiographic or surgical interventions (Cotton et al., 1991). Hospital admission and level of acuity are also critical descriptors. An adverse event that requires an unplanned hospital admission or prolongation of hospital stay for $<3$ nights is graded mild in severity compared to severe if requiring $>10$ nights or $>1$ night in ICU. Bleeding that requires transfusion or a repeat endoscopy is graded as moderate severity (Cotton et al., 2010). The traditional and new ERCPrelated bleeding severity grading scores suggested by Cotton et al. are collectively shown in Table 1 .

Table 1. Severity grading of the post ERCP bleeding

\begin{tabular}{|c|c|c|}
\hline \multicolumn{3}{|c|}{ Severity grading } \\
\hline Mild & Moderate & Severe \\
\hline $\begin{array}{l}\text { Either of the following: } \\
\text { - Clinical (not just endoscopic) } \\
\text { evidence of bleeding } \\
\text { - Hemoglobin drop }<3 \mathrm{gr} / \mathrm{dL} \text { and no } \\
\text { need for transfusion } \\
\text { - Abortion of procedure } \\
\text { - Unplanned admission }<4 \text { nights }\end{array}$ & $\begin{array}{l}\text { Any one of the following: } \\
\text { - Need for transfusion }(<4 \text { units }) \\
\text { - Repeat endoscopy or *interventional radiology } \\
\text { - Unplanned admission } 4-10 \text { nights } \\
\text { - ICU admission } 1 \text { night } \\
\text { - Intervention for integument injuries }\end{array}$ & $\begin{array}{l}\text { Any one of the following: } \\
\text { - Transfusion }>5 \text { units } \\
\text { - Unplanned admission }>10 \text { nights } \\
\text { - ICU admission }>1 \text { night } \\
\text { - Need for surgery } \\
\text { - Permanent disability }\end{array}$ \\
\hline
\end{tabular}

ICU, intensive care unit. *Radiology angiography intervention is classified as moderate severity grading in the new Cotton's grading system (Cotton et al., 2010). However, this was considered a serious situation according to the traditional severity grading system (Cotton et al., 1991)

\section{Risk factors}

The risk factors for ERCP-related bleeding can be categorized as patient-related, technique related and operator related factors. When evaluating a patient with post-ERCP bleeding, it is important to define the patient profile, including medical comorbidities, anatomical variants and medications.

A landmark prospective study by Freeman et al. described the rate of adverse events after endoscopic biliary sphincterotomy according to the patient, procedure, and endoscopic technique. Clinically significant bleeding occurred in $2 \%(\mathrm{n}=48)$ of 2453 patients included in this study and was mild at $0.6 \%$, moderate at $0.9 \%$ and severe at $0.5 \%$. Multivariable analysis identified 5 independent risk factors for post-ERCP bleeding (PEB), including three patient-related factors: the presence of coagulopathy, active cholangitis before the procedure and initiation of anticoagulant therapy within three days after ERCP. Endoscopist's mean case volume $(<1$ per week) was the only operator-related factor and the fifth risk factor was the occurrence of any observed bleeding during the procedure (Freeman et al., 1996). Risk factors for PEB in multivariate analyses are shown in Table 2 (Srinivasan and Fre, 2019).

\subsection{Patient- related factors}

The role of anticoagulants and antiplatelets in post-ERCP bleeding has been a topic of interest as the use of antithrombotic therapy, as well as dual antiplatelet agents (APA) and acetylsalicylic acid (ASA) increases the risk of bleeding. Current guidelines suggest withholding APAs (not ASA) before ERCP. In Patients who start on anticoagulation within 3 days after ERCP due to any coagulopathies have an increased the risk of PEB. ASA or NSAIDs in the periprocedural period is safe and does not increase the risk of bleeding after ERCP. Current guidelines suggest that low doses of aspirin or NSAIDs may be continued safely in the periendoscopic period.

Table 2. Risk factors for PEB in most studies analyses

\begin{tabular}{|c|c|c|}
\hline $\begin{array}{c}\text { Definite } \\
\text { (Significant by } \\
\text { multivariate } \\
\text { analyses) }\end{array}$ & $\begin{array}{c}\text { Maybe } \\
\text { (Significant by } \\
\text { univariate analyses) }\end{array}$ & $\begin{array}{c}\text { No } \\
\text { (Not significant by } \\
\text { multivariate } \\
\text { analyses) }\end{array}$ \\
\hline $\begin{array}{l}\text { - Coagulopathy } \\
\text { - Anticoagulation } \\
<3 \text { days after ES } \\
\text { - Cholangitis before } \\
\text { ERCP } \\
\text { - Bleeding during } \\
\text { ES } \\
\text { - Lower ERCP case } \\
\text { volume }\end{array}$ & $\begin{array}{l}\text { - Cirrhosis } \\
\text { - Dilated CBD } \\
\text { - CBD stone } \\
\text { - Periampullary } \\
\text { diverticulum } \\
\text { - Precut } \\
\text { sphincterotomy }\end{array}$ & $\begin{array}{l}\text { - Aspirin or } \\
\text { NSAID } \\
\text { - Ampullary tumor } \\
\text { - Longer length } \\
\text { - sphincterotomy } \\
\text { - Extension of prior } \\
\text { ES }\end{array}$ \\
\hline
\end{tabular}

Although the risk of bleeding associated with the use of a thienopyridine (ticlopidine, clopidogrel, and prasugrel) has not been well studied, it is recommended that these medications be discontinued at least five to seven days before high-risk endoscopic procedures (e.g., ERCP with sphincterotomy) with patients continued or switched to aspirin monotherapy until the thienopyridine can be safely resumed (Freeman et al., 1996; Acosta et al., 2016; Chandrasekhara et al., 2017). A recent South Korean study demonstrated at the timing of restarting anticoagulation and its impact on PEB in patients on warfarin 
bridged with heparin therapy around the time of their procedure. They found no difference in PEB with resumption time; however, there was an increased risk of thromboembolic events in the late resumption group (Paik et al., 2018). The precise role of the newer direct-acting, non-vitamin $\mathrm{K}$ oral anticoagulants (dabigatran, rivaroxaban, apixaban, and edoxaban) on risk of bleeding requires further investigation.

Cirrhosis, renal disease and dialysis for end-stage renal disease (particularly year-long hemodialysis), were confirmed as risk factors for ERCP-related bleeding in a meta-analysis and retrospective studies (Mashiana et al., 2018; Nakaji et al., 2018; Leal et al., 2019).

\subsection{Techniques and endoscopist related factors}

The role of precut is controversial: in two meta-analyses early precut sphincterotomy in difficult biliary access did not increase the rate of post-ERCP bleeding compared with persistent cannulation attempts (Sundaralingam et al., 2015; Tang et al., 2018). However, contrary to these meta-analyses, precut sphincterotomy has been associated with an increased incidence of bleeding in former multi-center studies (Loperfido et al., 1998; Masci et al., 2001).

PEB was less frequent with endoscopic sphincterotomy associated with balloon dilation vs. endoscopic sphincterotomy alone for difficult biliary stones (de Clemente et al., 2018). A recent meta-analysis reported that bleeding risk depend on the extent of the endoscopic sphincterotomy (Hwang et al., 2013).

As an endoscopic sphincterotomy technique, the papillae should be incised in the $10-11$ o'clock region, because this includes only $10 \%$ of all papillary arteries (Mirjalili and Stringer, 2011). Theoretically, it can be thought that bleeding may be less with this method. The type of current used during endoscopic sphincterotomy seems to affect the risk of ERCP related bleeding. Blended current, as opposed to pure-cut current, is recommended as it significantly reduces the incidence of bleeding without increasing the risk of post ERCP pancreatitis (Rey et al., 2010). Endocut may be preferred because it causes less bleeding compared to other blended current modes (Li et al., 2019). Endoscopist's case volume may also be another risk factor. One study reported that case volume $<1$ per week was an operator-related risk factor for post-ERCP bleeding (Freeman et al., 1996). Important factors that were not associated with bleeding included length of sphincterotomy incision, extension of prior sphincterotomy, the presence of a periampullary diverticulum or tumor and the use of aspirin or other NSAIDs within three days prior to procedure.

\section{Prevention of post-ERCP bleeding}

The risk of PEB can be minimized by identifying patients at risk, taking measures to correct coagulopathy, and using careful technique. The major method to reduce the risk of PEB is to avoid unnecessary sphincterotomy especially in patients with 1 or more risk factors. Prevention of PEB mandates careful patient assessment for risk factors and their correction whenever possible. An elective procedure provides the luxury of pre-procedure planning and preparations. Unfortunately, there may not be enough time to maintain optimum conditions in urgent procedures.

\subsection{Identifying patients at risk}

As a general rule, sphincterotomy is a high risk for bleeding in patients with advanced liver disease, kidney diseases, hemodialysis, and hemostasis disorders such as hemophilia and von Willebrand disease. Therefore, necessary corrections should be made as much as possible in these patients if sphincterotomy is required. Post ERCP observation should be extended in patients with portal hypertension or cirrhosis, renal disease and, dialysis for end-stage renal disease (particularly year-long haemodialysis). Bleeding rates after ampullectomy range from two to 18 percent (Kang et al., 2017). For this reason, caution is recommended in patients with papillary tumours that will undergo ampullectomy. This is probably a risk factor for bleeding based on pathophysiological and technical concerns and clinical experience (Bickerstaff et al., 1990).

\subsection{Optimizing coagulation abnormalities}

The general approach is to obtain a pre-ERCP coagulation screening (complete blood count and prothrombin time / international normalized ratio [INR]), particularly if an intervention (such as sphincterotomy, ampullectomy) is anticipated. A platelet count exceeding 50,000 to 80,000 / micro-L and an INR $<1.5$ are generally found to be safe (Sherman et al., 1992; Sherlock and Dooley J, 1993; Henning et al.,1994; Freeman et al., 1996; Prat et al., 1996). The guidelines from the ASGE recommend coagulation studies only in selected patients with active bleeding, a known or suspected bleeding disorder (including a history of abnormal bleeding), an increased risk of bleeding due to medication use (e.g., use of anticoagulants, prolonged antibiotic use), prolonged biliary obstruction, malnutrition or other conditions associated with acquired coagulopathies (Pasha et al., 2014). However, some endoscopists restrict pre-ERCP coagulation screening to patients with elevated bilirubin, who are receiving an anticoagulant or who have a history of a bleeding diathesis (Egan et al., 2014.). If a patient has coagulopathy, this should be corrected and platelet count and INR should be maintained at $>50,000 /$ micro- $\mathrm{L}$ and less than 1.5 , respectively. If the ERCP procedure is not emergent, one could wait until correction of coagulopathy. Otherwise, emergent reversal of anticoagulation can be achieved with fresh frozen plasma.

Clotting defects in cirrhotic patients can be corrected with fresh-frozen plasma, vitamin $\mathrm{K}$ or platelet transfusion before ERCP (Boujaoudé et al., 1994; Prat et al., 1996). Patients with known platelet dysfunction such as patients on hemodialysis should receive appropriate preventive measures, which may include infusion of desmopressin (DDAVP) (Sidawy et al., 2008). Consultation with an expert in coagulation disorders is recommended before performing endoscopic procedures in patients with disorders of hemostasis. 
ASA, other NSAIDs and antiplatelet drugs (i.e., ticlopidine, clopidogrel, and prasugrel) have the potential to increase the risk of bleeding. The management of antiplatelet therapy can be individualized depending on weighing the procedural risk for bleeding with the risk of cardiovascular or thromboembolic events. Several professional societies recommend discontinuing clopidogrel and prasugrel before endoscopic sphincterotomy (5-7 days), while aspirin can be continued except ampullectomy (Boustière et al., 2011; Veitch AM et al., 2016).

For patients on warfarin therapy, British Society of Gastroenterology (BSG) and European Society of Gastrointestinal Endoscopy (ESGE) guidelines recommend that warfarin should be discontinued for five days to allow the INR to reduce to $<1.5$ to perform endoscopic sphincterotomy and high-risk procedure (Veitch AM et al., 2016). Patients at high risk of thromboembolic events (mechanical valves, atrial fibrillation with a history of CVA, or a CHADSVASC of >2) can be bridged with heparin in the periprocedural period. After the procedure, clopidogrel and warfarin may be started by $48 \mathrm{~h}$ post procedure depending on the perceived risk of bleeding and thrombosis. The novel direct oral anticoagulants (Dabigatran, Rivaroxaban, Apixaban, Edoxaban) should be stopped $>2$ halflives before the procedure, which depends on the specific agent and the patient's renal function. The optimal timing for restarting antithrombotic therapy after ERCP intervention will depend on the perceived risk of post-procedural bleeding and thrombosis. Detailed advice on the management of anticoagulants and antiplatelet agents in the context of ERCP is available in the BSG/ ESGE Guidelines. (Dumonceau et al., 2020).

\subsection{Endoscopic techniques}

One of the important bleeding prevention approaches is the technique of sphincterotomy because sphincterotomy is the main cause of PEB. Papilla cutting length, sphincterotome type, electrocautery current mode, selection of balloon dilatation against sphincterotomy in the extraction of gallstones, submucosal injection is some of the endoscopic methods affecting the chances of PEB occurrence. The experience of the endoscopist and the volume of the center are directly related to the risk of ERCP related bleeding. The risk of PEB increases with sphincterotomy performed by relatively inexperienced endoscopists or when the volume of the endoscopy unit is low. Improvement in endoscopic methods may explain the slight decrease in the sphincterotomy-induced bleeding rate observed over time (Lee et al., 2020).

PEB can be prevented or restricted by proper orientation of the guidewire, avoidance of "zipper or Y type" cuts and unnecessarily long cuts, and judicious use of the electrocautery current (Ratani et al., 1999). The papillae should be incised in the 10-11 o'clock region. Optimal electrocautery settings are uncertain because of a trade-off in the risk of pancreatitis versus bleeding. Pure-cut electrocautery current is associated with an increase in the frequency of localized bleeding, which may temporarily obscure the view and interfere with the procedure (Ratani et al., 1999). Blended current is recommended as it significantly reduces the incidence of bleeding without increasing the risk of post ERCP pancreatitis (Rey et al., 2010). The use of combined current sphincterotomy technic (pure-cut and blended current in sequence, starting with pure cut and completing the sphincterotomy with the blended current) did not reduce the rate of clinically significant post-sphincterotomy bleeding in comparative studies (Stefanidis et al., 2003). Our practise is to use ENDO CUT mode (ERBE, Germany).

Endoscopic balloon dilatation (EBD) for the treatment of bile duct stones in patients with hemostatic disorder may reduce the risk of PEB compared to standard sphincterotomy. In particular, the technique of combining small (1/3) sphincterotomy with balloon dilatation is safe and may alleviate the risk of perforation and bleeding (Mok et al. 2017)

The rationale for using closed or partially closed sphincterotome is to provide a more controlled cut and avoid the "zipper" cut. Although this seems theoretically logical, the use of a partially closed sphincterotome was not associated with lower PEB compared to the results with a closed sphincterotome (Katsinelos et al., 2010).

Prophylactic submucosal injections have also been investigated to prevent bleeding after sphincterotomy. In a randomized prospective study, prophylactic submucosal injection of hypertonic saline-epinephrine has been shown to be effective in preventing PEB (Matsushita et al., 2010). Additional studies are needed to determine whether this technique will be routinely applied to patients with increased bleeding.

\section{Management of post-ERCP bleeding}

PEB often stops spontaneously and is rarely life-threatening. But PEB may become a big problem in patients with bleeding diathesis or hemostatic disorders. Most clinically significant bleeding can be managed with like any other cause of gastrointestinal bleeding such as medical treatment and endoscopic therapy, which should be performed without delay in patients who have immediate bleeding. The importance of resuscitation and medical treatment should not be ignored in all gastrointestinal bleeding cases. The first and major life saving steps include adequate intravenous replacement (fluid and/or blood products) and hemodynamic resuscitation and medical stabilization. Endoscopic therapy, pharmacologic treatment, angiographic treatment, and surgery are medical options for the current treatment of PEB. Angiography or surgery is rarely required for patients with refractory bleeding.

\subsection{Endoscopic therapy}

Several endoscopic techniques, such as injection therapy, mechanical methods, and thermal methods, are used to control bleeding. It is critical and particularly important to avoid any trauma in the pancreatic orifice located below the lower rim of 
the sphincterotomy when performing one of the endoscopic haemostasis procedures. Accidental but well-intentioned endoscopic intervention in this area can cause acute pancreatitis.

\subsection{Injection therapies}

The most used and generally effective endoscopic intervention is injection therapy with diluted epinephrine $(1: 10,000)$ through a sclerotherapy needle into and around the sphincterotomy site (Boujaoudé et al., 1994; Vásconez et al., 1998). The volume of injectate varies between studies but usually is $0.5 \mathrm{ml}$ to $4 \mathrm{ml}$. It is effective on controlling bleeding by volume tamponade and local vasoconstriction. The technique is easy to learn and does not damage to tissues. However, diluted epinephrine does not cause vascular thrombosis. Injection of sclerosing agents in combination with epinephrine has also been described, but extreme caution should be exercised when injecting sclerosing agents due to the risk of inflammatory or necrotic effects (Chester and Hurley, 1990). The effect of endoscopic haemostasis with epinephrine and/or alcohol injection therapy was illustrated effective and safe in a study of 1304 patients with 10 percent bleeding (Kim et al., 1999). Societal guidelines emphasize that epinephrine should always be combined with a second endoscopic therapy such as a mechanic or thermal method (high-grade recommendation). This recommendation can be applied to other GIS bleeding except for PEB because, as demonstrated in a retrospective study, epinephrine injection was as effective as epinephrine injection combined with thermal therapy for the management of delayed PEB (respectively; haemostasis $96 \%$ vs $100 \%$ and re-bleeding $16 \%$ vs $12 \%$ ) (Tsou et al., 2009). Therefore, injection therapies are the first-line treatment option, and if injection therapy fails, the second option may be other techniques or combinations.

The injection of fibrin sealant, a two-component adhesive consisting of human fibrin and thrombin with the addition of coagulation factor XIII, has also been successfully used to stop PEB in the case of rebleeding after injection therapy with epinephrine. The injection of a fibrin sealant has potential advantages over sclerosants. But, difficulty of preparation and injection, high cost, potential risk of transmission of infection, and possible occlusion of the pancreatic orifice are several drawbacks of fibrin sealant. So, before injection biliary and pancreatic outflow should be secured by placing pancreatic and biliary stents (Born et al., 2000). Injection of saline also causes local tamponade, which can be effective in achieving transient haemostasis. However, it is associated with higher recurrent bleeding rates compared with other standard therapies. It can be used to temporarily stop bleeding so that the endoscopist will have the chance to observe the bleeding area clearly while planning an intervention for permanently stopping the bleeding.

\subsection{Thermal methods}

Thermal coagulation with contact (heater or bipolar) or noncontact (argon plasma coagulation) probes achieves acute hemostasis and prevents recurrent bleeding by coagulation of the underlying artery in the bleeding area. The application of electrocautery current is more difficult than injection therapy because of the side view angle and elevator of duodenoscopy. But can be attempted with the sphincterotome wire or with an electrocautery, heater probe or argon plasma coagulation probe if a visible vessel or a specific bleeding point can be identified. If brisk bleeding occurs during the sphincterotomy procedure, electrocoagulation can be successfully completed without the need for another probe to change directly with the sphincterotome wire. The basic principles of electrocoagulation are the same as those used in other GIS bleeding. However, if thermal coagulation is required around the pancreatic orifice, the pancreatic stent should be placed first to prevent the development of potentially acute pancreatitis.

\subsection{Mechanical methods Hemoclip}

Endoscopic clips are a mechanical clamping method that has many potential therapeutic applications. While currently available clips are relatively easy to use, they require specific practice on the part of both the endoscopist and the assistant. When first-line therapy epinephrine injection or thermal methods fail or bleeding recurs hemostasis can be achieved by precise placement of one or more hemoclips at the bleeding site (Katsinelos et al., 2005). Accurate targeting with good position, best viewing angle and application direction is required for success. However, in case of active bleeding, it may be difficult to apply the clips with side-viewing duodenoscope. The duodenoscope elevator often makes clip delivery challenging because the plastic sheath often becomes kinked while passing through the elevator. This disadvantage can be facilitated by using a forward-view endoscope with a cover (Kubiliun et al., 2015). If necessary, the prophylactic pancreatic stent should be inserted first. In two studies (67 patients with persistent PEB), clips provided hemostasis in 90\%-100\% of the cases (Liu et al., 2015; Chon and Kim, 2017). A novel duodenoscopy-friendly hemoclips designed for delivery using the duodenoscope may also be used. Also, it is necessary to avoid around the pancreatic orifice with the associated risk of pancreatitis during the application of hemoclip.

\section{Balloon tamponade}

The balloon tamponade of the sphincterotomy site can be obtained with a standard stone removal balloon catheter (Freeman et al., 1996). However, this technique is practical for active intraprocedural bleeding that occurs during sphincterotomy. The balloon is inflated maximally, creates a tampon, and temporarily stops bleeding. Meanwhile, temporary control of bleeding improves visualization of the bleeding site and may allow plan and successfully implement other treatment methods. It is not usually a permanent bleeding stop treatment method and the effectiveness of this method has not been well studied. 


\section{Fully covered self-expandable metal stent}

Over the past decade, fully covered self-expandable metal stents (FCSEMs) have been used for refractory PEB with excellent clinical outcomes (Itoi et al., 2011; Canena et al., 2013). FCSEMSs also can be used to tamponade bleedings originating from deep within the ampulla or mid/distal common bile duct and can prevent the development of hemobilia. FCSEMs may be a particularly effective lastopportunity second-line method before resorting to embolization or surgery where primary endoscopic intervention has failed in PEB. A retrospective CEASE study included 67 patients with PEB found that, after the failure of primary endoscopic interventions, placement of a fully covered SEMS ( $n=23$ ) significantly reduced the bleeding rate at 72 hours and resulted in less of a decrease in hemoglobin level than that of conventional methods $(0.66 \mathrm{~g} / \mathrm{dL}$ vs. $1.98 \mathrm{~g} / \mathrm{dL}, \mathrm{P}$ $<0.001$ ) (Cochrane and Schlepp, 2016). There is no consensus among experts on the optimal stent diameter and the timing of stent removal. Stent migration also remains a concern. FCSEMSs are relatively expensive devices and need a repeat procedure for stent removal usually within 4-8 weeks to avoid adverse events related to long term indwelling stent.

\subsection{Hemostatic nanopowder and hemostatic agents}

A nanopowder that promotes hemostasis (Hemospray) has been developed that becomes cohesive and adhesive when it meets moisture, forming a stable mechanical barrier at the site of bleeding. It also has been shown to enhance clot formation and shorten coagulation time (Holster et al., 2015). The powder is delivered through a catheter and sprayed onto the bleeding site under endoscopic guidance. It is easy to apply, does not require an en face view of the ulcer, and does not require direct tissue contact. This treatment modality is available in Canada and Europe and was FDA approved in the United States in 2018. In a case of severe PEB, hemostasis was achieved through the application of $4 \mathrm{~g}$ of the hemostatic agent, with no evidence of secondary biliary obstruction (Appleby et al., 2015). The use of hemostatic nanopowder should be considered as a possible alternative to standard endoscopic therapy in cases where the position, site or size of the bleeding site makes conventional endoscopic therapy difficult.

Ankaferd Blood Stopper (ABS) (Ankaferd Sağlık ürünleri, A.Ş., İstanbul, Turkey), which is a commercial form of a traditional herbal medicine that has been used historically in Anatolia as a hemostatic agent for centuries, consists of a standardized mixture of five plants. ABS is locally active on the bleeding surface which is applied to the bleeding site and interacts with plasma proteins and acts by formation of an encapsulated protein network and stimulation of erythrocyte aggregation (Goker et al., 2008). Like the hemostatic nanopowder, it does not require injecting; spraying over the bleeding site is sufficient for hemostasis. Beyazit et al. reported that $3 \mathrm{~mL}$ of ABS was successfully applied and hemostasis was achieved in a 43-year-old woman with intraprocedural bleeding from the sphincterotomy site where electrocoagulation and injection therapy failed (Beyazit et al., 2010). Hemostatic powder, fibrin glue and other herbal hemostatic agents are possible rescue therapies, but the reported experience in the literature is extremely limited to just a few case reports and thus they cannot be routinely recommended.

\section{Pharmacologic treatment}

In the management of patients with disorders of hemostasis or coagulopathies who are undergoing ERCP, the disease severity, the procedure-related bleeding risk, and the timing of the procedure should be considered. The bleeding risk also depends on the patient's underlying disorder and the availability of interventions to enhance hemostasis (e.g., factor replacement for hemophilia, platelet transfusions for thrombocytopenia). Use of recombinant human factor VIIa as a preventive measure has also been reported in a patient with inherited factor VII deficiency who successfully underwent ERCP with sphincterotomy without bleeding (Abdulsamad et al., 2017). Infusion of terlipressin in four patients (Tyagi et al., 2009) and infusion of nitro-glycerine in another case report (Sharma 2010) were effective in controlling hemobilia during therapeutic ERCP in patients with portal biliopathy. In hemodialysis patients, the administration of desmopressin (DDAVP) infusion is an option to improve platelet dysfunction.

\section{Angiographic treatment}

In some cases, massive bleeding occurs during sphincterotomy and obscures the endoscopic field, which makes subsequent hemostatic procedures technically difficult and may result in the failure of the several endoscopic hemostatic methods. In these situations, bleeding needs to be stopped by radiologic or surgical intervention. Celiac or superior mesenteric angiography with transcatheter infusion of vasopressin or embolization of the bleeding artery can be effective but is uncommonly performed as underscored by the paucity of data on this approach. Arterial embolization is technically difficult and may cause infarction of abdominal organs. Therefore, it is necessary to target the right artery and make selective or super selective embolization as much as possible. Yamaguchi et al. reported that the papillary artery originates from the communicating artery which connects the posterior superior pancreaticoduodenal artery (PSPDA) and the anterior superior pancreaticoduodenal artery (ASPDA) (74\%), or directly from the posterior pancreaticoduodenal artery as a vasa recta type (26\%) among 73 papillary arteries. Furthermore, no papillary artery arises from the anterior pancreaticoduodenal artery, so the vessels targeted for vascular interventional treatments should be carefully and specifically selected (Yamaguchi et al., 2001). Studies have shown a reduction in the risk of bowel infarction due to technical improvements and increased experience of advanced interventional radiologists. Angiographic interventions successfully control bleeding in $83 \%$ to $100 \%$ of patients in reported series and should be considered before surgery (So et al., 2012; Dunne et al., 2013). 
Angiographic embolization also can be used for treatment of hemobilia originating from the locations proximal to the hilum and for distal bleedings that are refractory to FCSEMs placement.

\section{Surgery}

As mentioned above, the need for surgery has decreased during the past two decades because of success with several endoscopic methods. The most performed rescue operation involves conversion of the sphincterotomy into a sutured sphincteroplasty and oversewing the bleeding artery at the apex of the sphincterotomy. If anatomic changes make direct access to the ampulla through the duodenal wall impossible, a Fogarty catheter can be inserted into the common bile duct (either through the cystic duct or a choledochotomy) permitting balloon tamponade of the bleeding point (Bardaxoglou et al., 1994). In older series, surgery was associated with postoperative mortality rates as high as 50 percent, largely because many of the patients were too ill for surgery (Goodall, 1985). The infusion of a topical gelatin matrix-thrombin hemostatic agent into the distal portion of the common bile duct during urgent surgical exploration was effective in a patient with life-threatening PEB (Dimitroulis et al., 2012). Further experience is needed to confirm the efficacy of this topical hemostatic agent in cases of PEB. There have been no head-to-head trials comparing clipping, cautery or metal stents

\section{References}

1. Abdulsamad, M., Reddy, P., Guvvala, S., Dev, A., 2017. Recombinant Factor VIIa Use for Endoscopic Retrograde Cholangiopancreatography with Sphincterotomy in a Patient with Choledocholithiasis and Unusual Coagulopathy. Gastroenterology Res. 10, 144-146.

2. Appleby, V.J., Hutchinson, J.M., Beckett, C.J., Moreea, S., 2015. Use of the haemostatic agent TC-325 in the treatment of bleeding secondary to endoscopic retrograde cholangiopancreatography sphincterotomy. QJM. 108, 79-80.

3. ASGE Standards of Practice Committee, Acosta, R. D., Abraham, N. S., Chandrasekhara, V., Chathadi, K.V., Early, D.S., Eloubeidi, M.A., Evans, J.A., Faulx, A.L., Fisher, D.A., Fonkalsrud, L., Hwang, J.H., Khashab, M.A., Lightdale, J.R., Muthusamy, V.R., Pasha, S.F., Saltzman, J.R., Shaukat, A., Shergill, A.K., Wang, A., Cash, B.D., DeWitt, J.M., 2016. The management of antithrombotic agents for patients undergoing GI endoscopy. Gastrointest. Endosc. 831, 3-16.

4. ASGE Standards of Practice Committee, Chandrasekhara, V., Khashab, M.A., Muthusamy, V.R., Acosta, R.D., Agrawal, D., Bruining, D.H., Eloubeidi, M.A., Fanelli, R.D., Faulx, A.L., Gurudu, S.R., Kothari, S., Lightdale, J.R., Qumseya, B.J., Shaukat, A., Wang, A., Wani, S.B., Yang, J., DeWitt, J.M., 2017. Adverse events associated with ERCP. Gastrointest. Endosc. 85, 32-47.

5. ASGE Standards of Practice Committee, Pasha, S.F., Acosta, R., Chandrasekhara, V., Chathadi, K.V., Eloubeidi, M.A., Fanelli, R., Faulx, A. L., Fonkalsrud, L., Khashab, M.A., Lightdale, J.R., Muthusamy, V.R., Saltzman, J.R., Shaukat, A., Wang, A., Cash, B., 2014. Routine laboratory testing before endoscopic procedures. Gastrointest. Endosc. 80, 28-33.

6. Bardaxoglou, E., Campion, J.P., Maddern, G., Siriser, F., Launois, B., 1994. A simple method to control intractable bleeding after endoscopic sphincterotomy. Am. J. Surg. 167, for PEB, so various approaches can be utilized. Injection therapies and thermal methods are the first line option in daily practice. If the location of the suspected bleeding site allows the placement of hemostatic clips, it may be the second option to control bleeding when the first interventions fail. Balloon tamponade and injection of saline around the papilla ensure temporary control of bleeding, improves visualization of the bleeding site, and may allow plan and successful implementation other treatment methods. These approaches utilize the fundamental tools traditionally applied in other luminal causes of gastrointestinal bleeding. Caution should be taken to avoid thermal injury or clip placement over the pancreatic orifice, especially if the bleeding site is on the righthand wall of the sphincterotomy incision. The placement of a FCSEMs is probably best reserved as a salvage therapy when traditional endoscopic methods fail. Hemostatic powder, fibrin glue and another herbal hemostatic agent cannot be routinely recommended. Pharmacological agents can be used in chronic systemic diseases, disorders of hemostasis or coagulopathies. In rare cases, angiography or surgery is required for refractory bleeding.

\section{Conflict of interest}

None.

\section{Acknowledgments}

None.

\section{$277-278$.}

7. Beyazit, Y., Köklü, S., Akbal, E., Kurt, M., Kekilli, M., Haznedaroglu, I. C., 2010. Successful treatment of endoscopic sphincterotomy-induced early hemorrhage with application of Ankaferd Blood Stopper. Gastrointest. Endosc. 72, 1325-1326.

8. Bickerstaff, K.I., Berry, A.R., Chapman, R.W., Britton, B.J., 1990. Endoscopic sphincterotomy for the palliation of ampullary carcinoma. Br. J. Surg. 77, 160-162.

9. Boujaoudé, J., Pelletier, G., Fritsch, J., Choury, A., Lefebvre, J.F., Roche, A., Frouge, C., Liguory, C., Etienne, J.P., 1994. Management of clinically relevant bleeding following endoscopic sphincterotomy. Endoscopy. 26, 217-221.

10. Boustière, C., Veitch, A., Vanbiervliet, G., Bulois, P., Deprez, P., Laquiere, A., Laugier, R., Lesur, G., Mosler, P., Nalet, B., Napoleon, B., Rembacken, B., Ajzenberg, N., Collet, J.P., Baron, T., Dumonceau, J.M., European Society of Gastrointestinal Endoscopy, 2011. Endoscopy and antiplatelet agents. European Society of Gastrointestinal Endoscopy (ESGE) Guideline. Endoscopy. 43, 445-461.

11. Canena, J., Liberato, M., Horta, D., Romão, C., Coutinho, A., 2013. Short-term stenting using fully covered self-expandable metal stents for treatment of refractory biliary leaks, postsphincterotomy bleeding, and perforations. Surg. Endosc. $27,313-324$.

12. Chester, J.F. And Hurley, P.R., 1990. Gastric necrosis: a complication of endoscopic sclerosis for bleeding peptic ulcer. Endoscopy. 22, 287.

13. Chon, H.K., Kim, T.H., 2017. Endoclip therapy of postsphincterotomy bleeding using a transparent cap-fitted forwardviewing gastroscope. Surg. Endosc. 31, 2783-2788.

14. Cochrane, J., Schlepp, G., 2016. Comparing endoscopic intervention against fully covered self-expanding metal stent placement for post-endoscopic sphincterotomy bleed (CEASE 
Study). Endosc. Int. Open. 4, 1261-1264.

15. Cotton, P. B., Lehman, G., Vennes, J., Geenen, J. E., Russell, R. C., Meyers, W. C., Liguory, C., Nickl, N., 1991. Endoscopic sphincterotomy complications and their management: an attempt at consensus. Gastrointest. Endosc. 37, 383-393.

16. Cotton, P. B., Eisen, G. M., Aabakken, L., Baron, T. H., Hutter, M. M., Jacobson, B. C., Mergener, K., Nemcek, A., Jr, Petersen, B. T., Petrini, J. L., Pike, I. M., Rabeneck, L., Romagnuolo, J., Vargo, J. J, 2010. A lexicon for endoscopic adverse events: report of an ASGE workshop. Gastrointest. Endosc. 71, 446454.

17. de Clemente Junior, C. C., Bernardo, W. M., Franzini, T. P., Luz, G. O., Dos Santos, M., Cohen, J. M., de Moura, D., Marinho, F., Coronel, M., Sakai, P., de Moura, E., 2018. Comparison between endoscopic sphincterotomy vs endoscopic sphincterotomy associated with balloon dilation for removal of bile duct stones: A systematic review and meta-analysis based on randomized controlled trials. World. J. Gastrointest. Endosc. 10, 130-144.

18. Dimitroulis, D., Antoniou, E., Karidis, N. P., Kontzoglou, K., Kouraklis, G., 2012. Surgical control of life-threatening postERCP bleeding with a gelatin matrix-thrombin hemostatic agent. Int. J. Surg. Case. Rep. 3, 471-473.

19. Dumonceau, J. M., Kapral, C., Aabakken, L., Papanikolaou, I. S., Tringali, A., Vanbiervliet, G., Beyna, T., Dinis-Ribeiro, M., Hritz, I., Mariani, A., Paspatis, G., Radaelli, F., Lakhtakia, S., Veitch, A. M., \& van Hooft, J. E. 2020. ERCP-related adverse events: European Society of Gastrointestinal Endoscopy (ESGE) Guideline. Endoscopy. 52, 127-149.

20. Dunne, R., McCarthy, E., Joyce, E., McEniff, N., Guiney, M., Ryan, J. M., Beddy, P. 2013. Post-endoscopic biliary sphincterotomy bleeding: an interventional radiology approach. Acta. Radiol.. 54, 1159-1164.

21. Egan, R. J., Nicholls, J., Walker, S., Mellor, K., Young, W. T., Stechman, M. J., 2014. Routine coagulation screening is an unnecessary step prior to ERCP in patients without biochemical evidence of jaundice: a cross-centre study. Int. J. Surg. 12, 12161220.

22. Freeman, M. L., Nelson, D. B., Sherman, S., Haber, G. B., Herman, M. E., Dorsher, P. J., Moore, J. P., Fennerty, M. B., Ryan, M. E., Shaw, M. J., Lande, J. D., Pheley, A. M., 1996. Complications of endoscopic biliary sphincterotomy. N. Engl. J. Med. 335, 909-918.

23. Glomsaker,T., Hoff ,G., Kvaloy, J.T., Soreide ,K., Aabakken, L., Soreide, J.A., 2013. Patterns and predictive factors of complications after endoscopic retrograde cholangiopancreatography. Br. J. Surg. 100, 373-380.

24. Goker, H., Haznedaroglu, I. C., Ercetin, S., Kirazli, S., Akman, U., Ozturk, Y., Firat, H. C. 2008. Haemostatic actions of the folkloric medicinal plant extract Ankaferd Blood Stopper. J. Int. Med. Res. 36, 163-170.

25. Goodall, R. J., 1985 . Bleeding after endoscopic sphincterotomy. Ann. R. Coll. Surg. Engl. 67, 87-88.

26. Henning, H., Lightdale, C.J., Look, D., 1994. ContraindicationsCoagulation disorders. In: Color Atlas of diagnostic Laparoscopy, Stuttgart, Thieme, New York, 17.

27. Holster, I. L., van Beusekom, H. M., Kuipers, E. J., Leebeek, F. W., de Maat, M. P., Tjwa, E. T., 2015. Effects of a hemostatic powder hemospray on coagulation and clot formation. Endoscopy. 47, 638-645.

28. Hwang, J. C., Kim, J. H., Lim, S. G., Kim, S. S., Shin, S. J., Lee, K. M., Yoo, B. M., 2013. Endoscopic large-balloon dilation alone versus endoscopic sphincterotomy plus large-balloon dilation for the treatment of large bile duct stones. BMC Gastroenterol. 13, 15.

29. Itoi, T., Yasuda, I., Doi, S., Mukai, T., Kurihara, T., Sofuni, A., 2011. Endoscopic hemostasis using covered metallic stent placement for uncontrolled post-endoscopic sphincterotomy bleeding. Endoscopy. 43, 369-372.

30. Kang, S. H., Kim, K. H., Kim, T. N., Jung, M. K., Cho, C. M., Cho, K. B., Han, J. M., Kim, H. G., Kim, H. S., 2017. Therapeutic outcomes of endoscopic papillectomy for ampullary neoplasms: retrospective analysis of a multicenter study. BMC. Gastroenterol. 17, 69.

31. Kapral, C., Muhlberger, A., Wewalka, F., Duller, C., Knoflach, P., Schreiber, F., 2012. Quality assessment of endoscopic retrograde cholangiopancreatography: results of a running nationwide Austrian benchmarking project after 5 years of implementation. Eur. J. Gastroenterol. Hepatol. 24, 1447-1454.

32. Katsinelos, P., Paroutoglou, G., Beltsis, A., Gouvalas, A., Mimidis, K., Vlachakis, I., Chatzimavroudis, G., Papaziogas, B., 2005. Endoscopic hemoclip placement for postsphincterotomy bleeding refractory to injection therapy: report of two cases. Surg. Laparosc. Endosc. Percutan Tech. 15, 238-240.

33. Katsinelos, P., Paroutoglou, G., Kountouras, J., Chatzimavroudis, G., Zavos, C., Terzoudis, S., Katsinelos, T., Fasoulas, K., Gelas, G., Tzovaras, G., Pilpilidis, I., 2010. Partially covered vs uncovered sphincterotome and postendoscopic sphincterotomy bleeding. World. J. Gastroenterol. 16, 5077-5083.

34. Kim, H. J., Kim, M. H., Kim, D. I., Lee, H. J., Myung, S. J., Yoo, K. S., Park, E. T., Lim, B. C., Seo, D. W., Lee, S. K., Min, Y. I., 1999. Endoscopic hemostasis in sphincterotomy-induced hemorrhage: its efficacy and safety. Endoscopy. 31(6), 431-436.

35. Kubiliun, N. M., Adams, M. A., Akshintala, V. S., Conte, M. L., Cote, G. A., Cotton, P. B., Dumonceau, J. M., Elta, G. H., Fogel, E. L., Freeman, M. L., Lehman, G. A., Naveed, M., Romagnuolo, J., Scheiman, J. M., Sherman, S., Singh, V. K., Elmunzer, B. J., United States Cooperative for Outcomes Research in Endoscopy (USCORE), 2015. Evaluation of Pharmacologic Prevention of Pancreatitis after Endoscopic Retrograde Cholangiopancreatography: A Systematic Review. Clin. Gastroenterol. Hepatol. 13, 1231-1239.

36. Leal, C., Prado, V., Colan, J., Chavez-Rivera, K., Sendino, O., Blasi, A., Roura, P., Juanola, A., Rodriguez de Miguel, C., Pavesi, M., Gomez, C., Guarner, C., Guarner-Argente, C., Fernández, J., Cardenas, A., 2019. Adverse events and acute chronic liver failure in patients with cirrhosis undergoing endoscopic retrograde cholangiopancreatography: A multicenter matched-cohort study. Am. J. Gastroenterol. 114, 89-97.

37. Lee, H. J., Cho, C. M., Heo, J., Jung, M. K., Kim, T. N., Kim, K. H., Kim, H., Cho, K. B., Kim, H. G., Han, J., Lee, D. W., Lee, Y. S., 2020. Impact of Hospital Volume and the Experience of Endoscopist on Adverse Events Related to Endoscopic Retrograde Cholangiopancreatography: A Prospective Observational Study. Gut. Liver. 14, 257-264.

38. Li, D. F., Yang, M. F., Chang, X., Wang, N. N., Tan, F. F., Xie, H. N., Fang, X., Wang, S. L., Fan, W., Wang, J. Y., Yu, Z. C., Wei, C., Xiong, F., Liu, T. T., Luo, M. H., Wang, L. S., Li, Z. S., Yao, J., Bai, Y., 2019. Endocut Versus Conventional Blended Electrosurgical Current for Endoscopic Biliary Sphincterotomy: A Meta-Analysis of Complications. Dig. Dis. Sci. 64, 20882094.

39. Liu, F., Wang, G. Y., Li, Z. S., 2015. Cap-assisted hemoclip application with forward-viewing endoscope for hemorrhage induced by endoscopic sphincterotomy: A prospective case series study. BMC Gastroenterol. 15, 135. 
40. Loperfido, S., Angelini, G., Benedetti, G., Chilovi, F., Costan, F., De Berardinis, F., De Bernardin, M., Ederle, A., Fina, P., Fratton, A., 1998. Major early complications from diagnostic and therapeutic ERCP: A prospective multicenter study. Gastrointest Endosc. 48, 1-10.

41. Masci, E., Toti, G., Mariani, A., Curioni, S., Lomazzi, A., Dinelli, M., Minoli, G., Crosta, C., Comin, U., Fertitta, A., Prada, A., Passoni, G. R., Testoni, P. A., 2001. Complications of diagnostic and therapeutic ERCP: a prospective multicenter study. The Am. J. Gastroenterol. 96, 417-423.

42. Mashiana, H. S., Dhaliwal, A. S., Sayles, H., Dhindsa, B., Yoo, J. W., Wu, Q., Singh, S., Siddiqui, A. A., Ohning, G., Girotra, M., Adler, D. G., 2018. Endoscopic retrograde cholangiopancreatography in cirrhosis - a systematic review and meta-analysis focused on adverse events. World. J. Gastrointest. Endosc. 10, 354-366.

43. Matsushita, M., Takakuwa, H., Shimeno, N., Uchida, K., Nishio, A., Okazaki, K., 2010. Prophylactic injection of hypertonic saline-epinephrine oral to the papilla for prevention of postsphincterotomy bleeding. J. Clin. Gastroenterol. 44, 167170.

44. Mirjalili, S. A., Stringer, M. D., 2011. The arterial supply of the major duodenal papilla and its relevance to endoscopic sphincterotomy. Endoscopy. 43, 307-311.

45. Mok, S. R., Arif, M., Diehl, D. L., Khara, H. S., Ho, H. C., Elfant, A. B., 2017. Safety and efficacy of minimal biliary sphincterotomy with papillary balloon dilation (m-EBS+EPBD) in patients using clopidogrel or anticoagulation Endosc. Int. Open. 5, 157-164.

46. Nakaji, S., Hirata, N., Matsui, H., Shiratori, T., Kobayashi, M., Yoshimura, S., Kanda, K., Kawamitsu, N., Harasawa, H., 2018. Hemodialysis is a strong risk factor for post-endoscopic sphincterotomy bleeding in patients with choledocholithiasis. Endosc. Int. Open. 6, 568-574.

47. Paik, W. H., Lee, S. H., Ahn, D. W., Jeong, J. B., Kang, J. W., Son, J. H., Ryu, J. K., Kim, Y. T., 2018. Optimal time of resuming anticoagulant after endoscopic sphincterotomy in patients at risk for thromboembolism: a retrospective cohort study. Surg. Endosc. 32, 3902-3908.

48. Prat, F., Tennenbaum, R., Ponsot, P., Altman, C., Pelletier, G., Fritsch, J., Choury, A. D., Bernades, P., Etienne, J. P., 1996. Endoscopic sphincterotomy in patients with liver cirrhosis. Gastrointest. Endosc. 43, 127-131.

49. Ratani, R. S., Mills, T. N., Ainley, C. C., Swain, C. P., 1999. Electrophysical factors influencing endoscopic sphincterotomy. Gastrointest. Endosc. 49, 43-52.

50. Rey, J. F., Beilenhoff, U., Neumann, C. S., Dumonceau, J. M., European Society of Gastrointestinal Endoscopy (ESGE), 2010. European Society of Gastrointestinal Endoscopy (ESGE) guideline: the use of electrosurgical units. Endoscopy. 42, 764772.

51. Sharma, M., Babu, C. S., Dhiman, R. K., Chawla, Y., 2010. Induced hypotension in the management of acute hemobilia during therapeutic ERCP in a patient with portal biliopathy (with videos). Gastrointest. Endosc. 72, 1317-1319.

52. Sherlock, S., Dooley, J., 1993. Needle biopsy of the liver. In: Diseases of the Liver and Biliary System, 9th edition, Blackwell, Oxford, 33.

53. Sherman, S., Hawes, R. H., Nisi, R., Lehman, G. A., 1992. Endoscopic sphincterotomy - induced hemorrhage: treatment with multipolar electrocoagulation. Gastrointest. Endosc. 38,
123-126.

54. Sidawy, A. N., Spergel, L. M., Besarab, A., Allon, M., Jennings, W. C., Padberg, F. T., Jr, Murad, M. H., Montori, V. M., O'Hare, A. M., Calligaro, K. D., Macsata, R. A., Lumsden, A. B., Ascher, E., Society for Vascular Surgery, 2008. The Society for Vascular Surgery: clinical practice guidelines for the surgical placement and maintenance of arteriovenous hemodialysis access. J. Vasc. Surg. 48, 2-25.

55. Siiki, A., Tamminen, A., Tomminen, T., Kuusanmaki, P., 2012. ERCP procedures in a Finnish community hospital: a retrospective analysis of 1207 cases. Scand. J. Surg. 101, 45-50.

56. So, Y. H., Choi, Y. H., Chung, J. W., Jae, H. J., Song, S. Y., Park, J. H., 2012. Selective embolization for post-endoscopic sphincterotomy bleeding: technical aspects and clinical efficacy. Korean. J. Radiol. 13, 73-81.

57. Srinivasan, I. and Fre, M.L., 2019. Adverse Events of ERCP: Prediction, Prevention, and Management. ERCP, third edition. Baron, T.H., Kozarek R.A., Carr-Locke, D.L. Elsevier, Philedelpiha, 59-68.

58. Stefanidis, G., Karamanolis, G., Viazis, N., Sgouros, S., Papadopoulou, E., Ntatsakis, K., Mantides, A., Nastos, H., 2003. A comparative study of postendoscopic sphincterotomy complications with various types of electrosurgical current in patients with choledocholithiasis. Gastrointest. Endosc. 57, 192197.

59. Sundaralingam, P., Masson, P., Bourke, M. J., 2015. Early Precut Sphincterotomy Does Not Increase Risk During Endoscopic Retrograde Cholangiopancreatography in Patients with Difficult Biliary Access: A Meta-analysis of Randomized Controlled Trials. Clin. Gastroenterol. Hepatol. 13, 1722-1729.

60. Talukdar, R., 2016. Complications of ERCP. Best Pract. Res. Clin. Gastroenterol. 30, 793-805.

61. Tang, Z., Yang, Y., Yang, Z., Meng, W., Li, X., 2018. Early precut sphincterotomy does not increase the risk of adverse events for patients with difficult biliary access: A systematic review of randomized clinical trials with meta-analysis and trial sequential analysis. Medicine (Baltimore). 97, e12213.

62. Tsou, Y. K., Lin, C. H., Liu, N. J., Tang, J. H., Sung, K. F., Cheng, C. L., Lee, C. S., 2009. Treating delayed endoscopic sphincterotomy-induced bleeding: epinephrine injection with or without thermotherapy. World. J. Gastroenterol. 15, 4823-4828.

63. Tyagi, P., Sachdeva, S., Agarwal, A. K., Puri, A. S., 2009. Terlipressin in control of acute hemobilia during therapeutic ERCP in patient with portal biliopathy. Surg. Laparosc. Endosc. Percutan. Tech. 19, 198-201.

64. Vásconez, C., Llach, J., Bordas, J. M., Ginès, A., Elizalde, J. I., Mondelo, F., Terés, J., 1998. Injection treatment of hemorrhage induced by endoscopic sphincterotomy. Endoscopy. 30, 37-39.

65. Veitch, A. M., Vanbiervliet, G., Gershlick, A. H., Boustiere, C., Baglin, T. P., Smith, L. A., Radaelli, F., Knight, E., Gralnek, I. M., Hassan, C., Dumonceau, J. M., 2016. Endoscopy in patients on antiplatelet or anticoagulant therapy, including direct oral anticoagulants: British Society of Gastroenterology (BSG) and European Society of Gastrointestinal Endoscopy (ESGE) guidelines. Gut. 65, 374-389.

66. Yamaguchi, H., Wakiguchi, S., Murakami, G., Hata, F., Hirata, K., Shimada, K., Kitamura, S., 2001. Blood supply to the duodenal papilla and the communicating artery between the anterior and posterior pancreaticoduodenal arterial arcades. J. Hepatobiliary Pancreat. Surg. 8, 238-244. 